\title{
GT2010-22189
}

\section{THERMODYNAMIC AND ECONOMIC EVALUATION OF AN IGCC PLANT BASED ON THE GRAZ CYCLE FOR CO2 CAPTURE}

\author{
W. Sanz, M. Mayr, H. Jericha \\ Institute for Thermal Turbomachinery and Machine Dynamics \\ Graz University of Technology, Graz, Austria \\ wolfgang.sanz@tugraz.at
}

\begin{abstract}
The IEA World Energy Outlook 2009 predicts a considerable growth of the world's primary energy demand and states that fossil fuels will remain the dominant source of primary energy. Among them coal will increase its share because of its vast reserves, its relatively even global distribution and its low prices compared to oil and gas. On the other hand the burning of coal emits larger quantities of $\mathrm{CO}_{2}$ than oil and gas. As $\mathrm{CO}_{2}$ is the leading cause for global warming, the use of coal for power generation demands a clean coal technology with carbon capture and storage (CCS).

Therefore in this work it is suggested to combine a coal gasification unit with a Graz Cycle power plant, an oxy-fuel technology of highest efficiency. The firing of the syngas from coal gasification with pure oxygen avoids the expensive precombustion $\mathrm{CO}_{2}$ sequestration and leads to a working fluid of $\mathrm{CO}_{2}$ and steam, where $\mathrm{CO}_{2}$ is captured by simple steam condensation. In contrast to this, the more conventional technology is to send the syngas to a water-shift reactor and a $\mathrm{CO}_{2}$ scrubber so that a fuel containing mainly hydrogen is obtained which can be fired in a conventional combined cycle plant.

In order to evaluate these two competing technologies a thermodynamic simulation as well as an economic cost analysis of both power cycles is performed. It turns out that the achievable efficiency of the Graz Cycle plant is - despite of the increased oxygen demand - far higher than that of a plant of conventional capture technology due to the avoidance of shift reaction and scrubbing. The following economic analysis shows mitigation costs of $22.5 € /$ ton $\mathrm{CO}_{2}$ avoided for the Graz Cycle plant compared to $33 € /$ ton for an IGCC plant with $\mathrm{CO}_{2}$ capture.
\end{abstract}

\section{INTRODUCTION}

The recent years have shown a dramatic increase in damages all around the world with loss of properties and lives and with dramatic changes in geographic regions like the Artic, the Antarctic, the high seas and all mountain ranges. All this is considered to be caused by man-made changes of climate, mainly by the extensive use of fossil fuels.

Therefore more and more people around the world recognize their obligations to save fossil fuels and to reduce emissions. On the other hand, the world's thirst for energy is still growing and fossil fuels will remain the dominant source of energy in the near future. Especially coal with its high carbon content will increase its share in power production because of its vast reserves and the relatively even distribution worldwide [1]. Therefore innovative coal technologies are indispensable for climate protection. In this respect, carbon capture and storage (CCS) plays a key role in the future use of coal.

There are three main ways to capture the carbon dioxide $\mathrm{CO}_{2}$ in coal fired power plants:

- removal of the $\mathrm{CO}_{2}$ from the exhaust gas (postcombustion technology)

- coal gasification and water-shift reaction of the syngas to produce a gas consisting mainly of $\mathrm{CO}_{2}$ and hydrogen $\mathrm{H}_{2}$. The $\mathrm{CO}_{2}$ can then be captured at relatively low costs leaving mainly $\mathrm{H}_{2}$ for the use in a conventional combined cycle plant (pre-combustion technology)

- $\quad$ use of oxygen instead of air for combustion leading to a flue gas consisting mainly of $\mathrm{CO}_{2}$ and $\mathrm{H}_{2} \mathrm{O}$, which allows an easy $\mathrm{CO}_{2}$ capture by water condensation (oxy-fuel technology). 
It is not clear, which technology will prevail in the future, but it can be expected that each technology will play a role in a future CCS market depending on the specific application. As an alternative to the pre-combustion technology demanding an energy-intensive shift reaction and $\mathrm{CO}_{2}$ scrubbing, a combination of coal gasification with an oxy-fuel cycle of highest efficiency, the Graz Cycle, is proposed in this work. Firing of the syngas with oxygen leads to a flue gas where the $\mathrm{CO}_{2}$ can be captured by water condensation and thus avoiding shift reactors and $\mathrm{CO}_{2}$ scrubber ahead of the combustor. This proposal of an oxy-fuel coal power plant is more complex than the firing of coal with oxygen in a boiler, as is currently investigated in a pilot plant in Germany [2], but promises much higher efficiencies. So Lozza et al. [3] conclude in their work that IGCC (integrated gasification combined cycle) oxycombustion techniques have a potential to improve the efficiency and the environmental characteristics of coal power plants.

The Graz Cycle system, an oxy-fuel cycle with internal combustion of fossil fuels with pure oxygen, was first presented by Jericha et al. in 1995 [4]. Since then Graz University of Technology has been working on it continuously, proposing thermodynamic layout and design of all main components, e.g. [5-12]. So at the ASME IGTI conference 2008 in Berlin a 600 MW plant with gas turbine inlet conditions of 50 bar and $1500^{\circ} \mathrm{C}$ was presented [13].

In this work a Graz Cycle plant of $400 \mathrm{MW}$ arranged downstream of a coal gasification unit is investigated. In order to reduce the heat losses of the gasifier, gasification and power plant are closely connected, with heat transferred between both units. In order to find out the thermodynamic benefits of this plant, it is compared with an IGCC plant with $\mathrm{CO}_{2}$ capture, where additional shift reactors and a $\mathrm{CO}_{2}$ scrubber are arranged in order to supply nearly pure $\mathrm{H}_{2}$ to an air-breathing combined cycle plant.

In a final economic evaluation both power plants with $\mathrm{CO}_{2}$ capture are compared with a conventional IGCC plant where the generated $\mathrm{CO}_{2}$ is released to atmosphere.

\section{ASSUMPTIONS ON PLANT CONFIGURATION}

As the goal of this work is to see if an IGCC plant based on the Graz Cycle shows any benefits compared to a "conventional" IGCC plant with carbon capture, not a certain existing gasification technology as the Shell or Texaco process has been taken. Knowing that this does not give quantitative information for a practical application, it surely allows a reliable qualitative conclusion on its merits.

For the gasification an entrained-flow technology was assumed which is a widely used large-scale technology for power generation. According to [14] gasifier temperature for this technology starts at $900^{\circ} \mathrm{C}$ and goes up to nearly $2000^{\circ} \mathrm{C}$, the working pressure ranges from $20-80$ bar. For this basic investigation a gasifier temperature of $900^{\circ} \mathrm{C}$ and a pressure of 25 bar are chosen. This relatively low reaction temperature positively impacts burner and refractory life and decreases costs [14]. Dry feed of the coal is assumed via lock hoppers but pressurization with nitrogen is not considered in this simplified approach. The products of the coal gasification are estimated with the method of the minimum Gibbs energy according to [15]. The reactions of sulfur are not yet implemented in the gasifier model so that $\mathrm{COS}$ hydrolysis and $\mathrm{H}_{2} \mathrm{~S}$ removal could not be considered in this approach. But additional losses are included in the balance which account for the sulfur handling.

The water-gas shift reaction for $\mathrm{CO}$ conversion is modeled in two temperature steps. The temperature levels are chosen to get optimum values for the recovery of the heat of reaction. The product gas composition is again modeled according to [15] and thus is a function of the reactor exit temperature.

Oxygen for the gasifier and the combustion is produced by cryogenic air separation. In most cases, $50 \%$ of the compressed air is extracted from the gas turbine [16], but all configurations, ranging from complete to zero integration can be used. For this investigation the air separation unit is assumed as a totally stand-alone unit, for the Graz Cycle plant integration is not possible.

Large cryogenic air separation units providing oxygen with a purity larger than $99.5 \%$ are operated today e.g. for chemical production plants from coal [17]. For IGCC plants low purity oxygen (about $95 \%$ ) is sufficient, but the reduction in power consumption is below $3 \%$ if no further advanced technologies are used [18]. Therefore for this investigation $99 \%$ oxygen purity is assumed because this reduces the fraction of noncondensable gases in the condenser of the Graz Cycle plant.

Normally the thermal sizing of an IGCC plant depends on the gas turbine model selected. Since the Graz Cycle needs a newly developed gas turbine due to the unusual working fluid, it was decided to determine the thermal input for a given net power cycle power output of $400 \mathrm{MW}$, which allows a better comparison of the necessary turbomachinery sizes. For the steam cycle of the IGCC plant, a dual-pressure reheat cycle instead of the conventional assumption of a triple-pressure cycle is modeled for simplicity reasons.

For the $\mathrm{CO}_{2}$ scrubbing in IGCC plants physical absorption methods (e.g. with Selexol) promise a lower energy consumption than chemical absorption due to the relatively high $\mathrm{CO}_{2}$ contents of syngas, especially if $\mathrm{H}_{2} \mathrm{~S}$ and $\mathrm{CO}_{2}$ are cosequestered in the same process $[3,16]$. But also chemical absorption with aqueous amines solutions is proposed for the removal of $\mathrm{CO}_{2}$ in IGCC, e.g. [19], and in this work a chemical absorption process with MEA is considered as a well assessed technology.

Finally, the composition of coal is assumed according to [20] with following mass fractions: $73.2 \% \mathrm{C}, 4.9 \% \mathrm{H}, 1.6 \% \mathrm{~N}$, $6.6 \% \mathrm{O}, 4.1 \%$ water and $9.6 \%$ ash. The sulfur content of the coal is neglected since the sulfur reactions have not yet been implemented in the simulation models. Therefore this coal cannot be related to a certain country. The LHV of this type of coal is $29.342 \mathrm{MJ} / \mathrm{kg}$. The coal supply to the gasifier is determined by the request of a net electrical output of the plant of $400 \mathrm{MW}$. 


\section{THERMODYNAMIC LAYOUT}

All thermodynamic simulations were performed using the commercial software IPSEpro by SIMTECH Simulation Technology [21]. This software allows the implementation of user-defined fluid properties to simulate the real gas properties of the cycle medium as well as to add new models to the model library as the gasifier. The cycle medium of the Graz Cycle plant is simulated as an ideal mixture of the real gases steam and $\mathrm{CO}_{2}$ and the ideal gases oxygen and nitrogen.

The efficiencies and losses of the components of the power cycles were agreed with an industry partner in the course of a thermodynamic evaluation of the Graz Cycle and can be found in [10]. Some important assumptions and differences to [10] are listed here again: 1) The isentropic efficiency of the cooled gas turbines is $90.3 \%$ and includes the flow losses due to cooling. It corresponds to a polytropic efficiency of $85.5 \%$. The demand of cooling flow is calculated as described in [12] for the Graz Cycle gas turbine or set by the request of an ISO turbine inlet temperature of $1300^{\circ} \mathrm{C}$ for a peak temperature of $1400^{\circ} \mathrm{C}$ of the air-breathing gas turbine. 2) The condensation pressure is set to 0.023 bar for a cooling water temperature of $10^{\circ} \mathrm{C}$ as reported for Danish power plants [22]. 3) The allowable minimum temperature difference in the evaporators is $5^{\circ} \mathrm{C}$, in the pre-heating and superheating section of the heat recovery steam generator as well as in the gas-to-gas heat exchangers it is $15^{\circ} \mathrm{C}$. 4) The pressure losses in the heat exchangers are $0.3 \%$ on the hot and cold side, an additional pressure loss of $5 \%$ is considered for the syngas cleaning. 5) Oxygen production is considered with an effort of $900 \mathrm{~kJ} / \mathrm{kg}$ $(0.25 \mathrm{kWh} / \mathrm{kg})$ at a purity of $99 \%$. It is delivered at a pressure of 2.38 bar from the air separation unit, so that the compression to the gasifier pressure of 25 bar needs $240 \mathrm{~kJ} / \mathrm{kg}$, to the Graz Cycle combustion pressure $325 \mathrm{~kJ} / \mathrm{kg}$. 6) Both cycles deliver the captured $\mathrm{CO}_{2}$ at different pressures and it is then compressed to 100 bar for transport and storage. The intercooled compression from 1.7 bar (Graz Cycle) is considered in the power balance with a value of $310 \mathrm{~kJ} / \mathrm{kg} \mathrm{CO}_{2}$, from 20 bar (IGCC plant) with $85 \mathrm{~kJ} / \mathrm{kg} \mathrm{CO}_{2}$. 7) Auxiliary losses, which could not be considered in this simplified approach, as gasifier and combustion chamber heat loss, coal treatment, operation of cooling water pumps or the syngas cleaning, are considered with $3 \%$ of the total heat input .

In the following the two power plants with $\mathrm{CO}_{2}$ capture which are compared in this investigation will be described in detail.

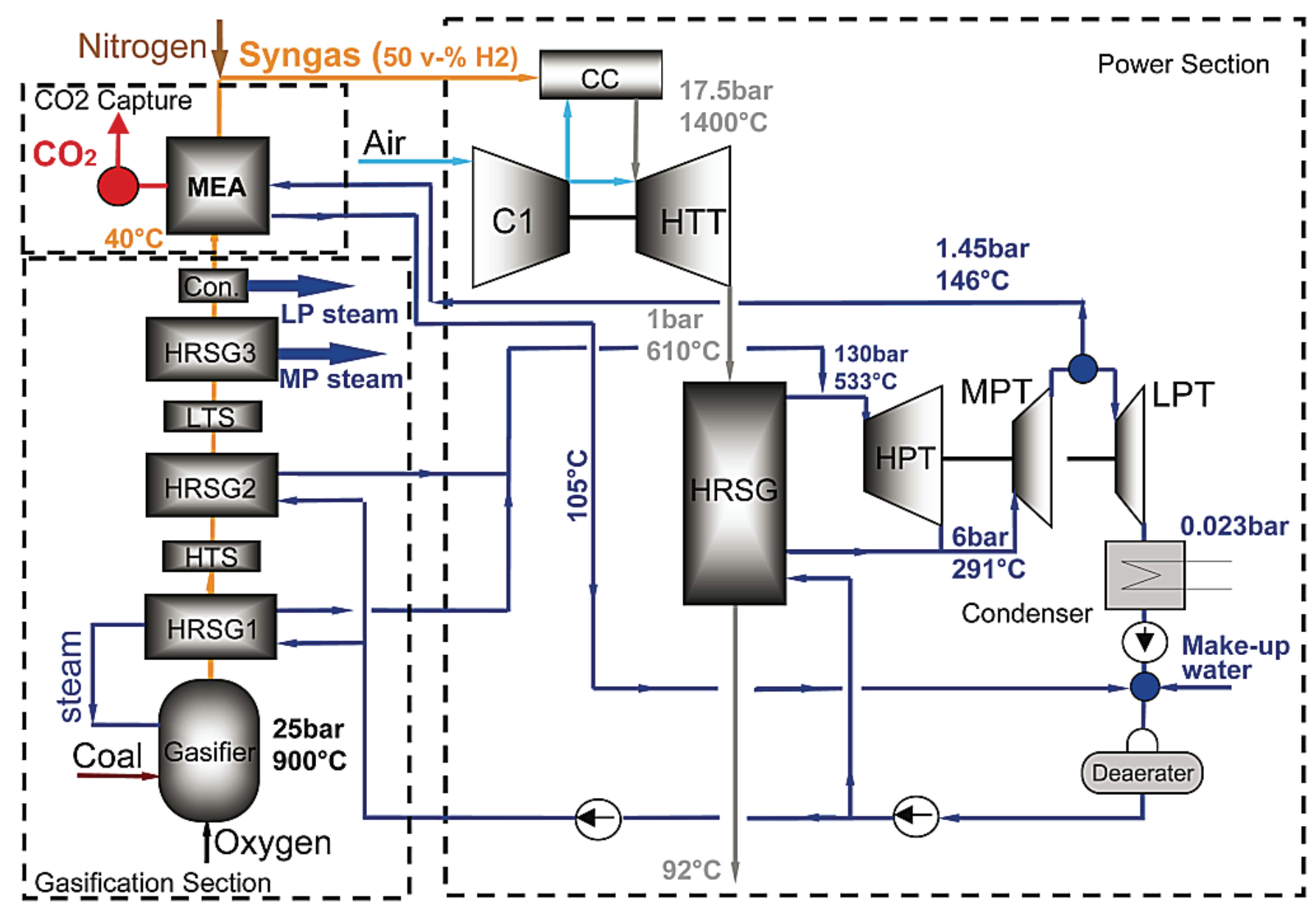

Fig. 1: Flow scheme of an IGCC power plant with pre-combustion $\mathrm{CO}_{2}$ capture 


\section{IGCC PLANT WITH $\mathrm{CO}_{2}$ CAPTURE}

Figure 1 shows the principle flow scheme of the IGCC plant with pre-combustion sequestration of the $\mathrm{CO}_{2}$ as investigated in this work. The plant consists of three main sections for the gasification, the power generation and the $\mathrm{CO}_{2}$ capture.

Gasification section: The thermal input to the gasifier is $1033 \mathrm{MJ} / \mathrm{s}(35.22 \mathrm{~kg} / \mathrm{s}$ coal $)$ to achieve a net electrical output of $400 \mathrm{MW}$. The auto-thermal reactor works at relatively low conditions of 25 bar and $900^{\circ} \mathrm{C}$. Oxygen of $99 \%$ purity and steam as reactant are also fed to the gasifier. Oxygen is compressed in an inter-cooled compressor and delivered to the gasifier at a temperature of $150{ }^{\circ} \mathrm{C}$. The necessary substoichiometric amount of oxygen of $27.1 \mathrm{~kg} / \mathrm{s}$ (stoichiometric ratio is 0.323 ) is determined from the request of $900^{\circ} \mathrm{C}$ reaction temperature for a gas composition imposed by the chemical equilibrium, considering a steam-to-coal ratio of 1.4. This ratio has been found by an imposed carbon capture rate of $90 \%$. Fig. 2 shows the influence of the steam-to-coal ratio on the $\mathrm{CO}_{2}$ capture capability. Reducing the ratio to 1.2, only $82.5 \%$ of the carbon can be retained. On the other hand, the net plant efficiency would increase by $1.7 \%$-points.

The main components of the syngas leaving the gasifier are $22.5 \% \mathrm{CO}, 13.9 \% \mathrm{CO}_{2}, 35.0 \% \mathrm{H}_{2}$ and $27.5 \% \mathrm{H}_{2} \mathrm{O}$ (vol- $\%$, see Table 1). The syngas is cooled to $380^{\circ} \mathrm{C}$ in the following heat recovery steam generator (HRSG1) producing steam for the gasifier of 25 bar as well as high-pressure steam of 130 bar for the steam cycle. In order to capture the carbon from the syngas prior to combustion, it is necessary to convert most of the $\mathrm{CO}$ from the gasification process into $\mathrm{CO}_{2}$ by applying the water-shift reaction. In the high-temperature shift reactor (HTS) $\mathrm{CO}$ reacts with steam yielding $\mathrm{CO}_{2}$ and $\mathrm{H}_{2}$ (water gas shift), so that the hydrogen content increases to $49.7 \%$ and the $\mathrm{CO}$ content decreases to $7.7 \%$ (see Table 1). In this mildly exothermic reaction the syngas temperature increases to $533^{\circ} \mathrm{C}$,

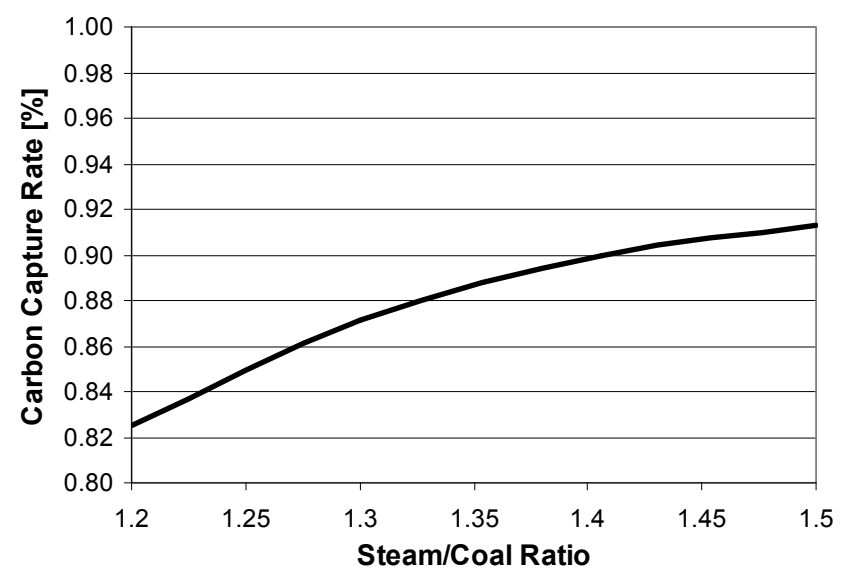

Fig. 2: Carbon capture rate as function of the steam-to-coal ratio for the IGCC plant with $\mathrm{CO}_{2}$ capture
Table 1: Syngas composition in vol-\% for the IGCC plant with $\mathrm{CO}_{2}$ capture

\begin{tabular}{|l|c|c|c|c|c|}
\hline Location & $\mathbf{H}_{\mathbf{2}}$ & $\mathbf{C O}$ & $\mathbf{C O}_{\mathbf{2}}$ & $\mathbf{H}_{\mathbf{2}} \mathbf{O}$ & $\mathbf{N}_{\mathbf{2}}$ \\
\hline Gasifier exit & 35.0 & 22.5 & 13.9 & 27.5 & 1.1 \\
\hline HTS exit & 49.7 & 7.7 & 28.7 & 12.8 & 1.1 \\
\hline LTS exit & 55.5 & 1.9 & 34.5 & 7.0 & 1.1 \\
\hline Condenser exit & 59.4 & 2.1 & 36.9 & 0.4 & 1.2 \\
\hline MEA exit & 91.6 & 3.2 & 2.9 & 0.5 & 1.8 \\
\hline Combustor inlet & 50.0 & 1.7 & 1.6 & 0.3 & 46.4 \\
\hline
\end{tabular}

so that in the following heat recovery steam generator HRSG2 further high-pressure steam can be produced. After the cooling of the syngas in the HRSG2 a further water shift reaction takes place in the low-temperature shift reactor (LTS), reducing the CO content to only $1.9 \%$ and increasing the $\mathrm{H}_{2}$ content to 55.5 $\%$ (see Table 1). The LTS exit temperature of the syngas is $290^{\circ} \mathrm{C}$ and thus far too high for a chemical absorption of $\mathrm{CO}_{2}$. Therefore in the HRSG3 further steam of 6 bar for the medium pressure turbine is generated. In the following syngas condenser the steam content is reduced to $0.4 \%$. The condensation heat can be partly used to generate steam of 1.5 bar for the low-pressure turbine, the very-low-temperature heat is cooled away (not shown in the simplified scheme of Fig. 1). The syngas leaves the condenser at a temperature of $40^{\circ} \mathrm{C}$, which promises high absorption rates in the following $\mathrm{CO}_{2}$ capture unit [23].

Before the syngas from coal gasification can be fed to the absorption process or to a gas turbine combustion chamber it must be cleaned. The typical steps for a gas clean-up system are aimed at particulate, sulfur, ammonia, and chlorides removal. Particulate removal is performed with cyclone and membrane filters, whereas the acid gas removal is done by chemical [19] or physical absorption [3, 16]. The syngas cleaning is not modeled in this investigation, but it is considered in the power balance by an additional effort of $2.2 \%$ of the thermal heat input (a value estimated from [24]; it is included in the auxiliary losses of $3 \%$, see above) and by a $5 \%$ pressure loss of the syngas flow.

$\mathrm{CO}_{2}$ capture section: $\mathrm{CO}_{2}$ separation from gaseous mixtures can be carried out by means of different processes. Among them, chemical absorption using monoethanolamine (MEA) is an available and common technology [19, 25]. The capture plant consists of two main elements, the $\mathrm{CO}_{2}$ absorber and the amine stripper (see Fig. 3). The flue gas containing $\mathrm{CO}_{2}$ enters the absorber and contacts an aqueous solution of MEA flowing countercurrently to the flue gas stream. $\mathrm{CO}_{2}$, a weak base, reacts exothermically with MEA, a weak acid, to form a water soluble salt. The 'rich' MEA stream exits the absorber at the bottom of the column. It is then preheated in a heat exchanger by the lean MEA stream leaving the stripper and then enters the stripper. There, with the further addition of heat, 


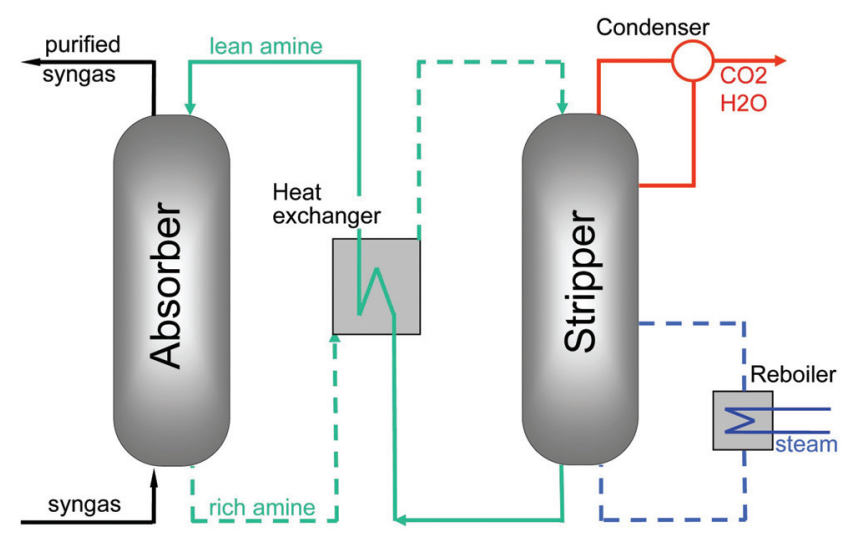

Fig. 3: Basic flow sheet of MEA $\mathrm{CO}_{2}$ capture process

the reaction is reversed. The $\mathrm{CO}_{2}$ liberated from the MEA leaves through the top of the stripper column, whereas the 'lean' MEA is recycled back to the absorber [23].

The heat required for the regeneration of the MEA sorbent is provided by steam via the reboiler and presents the main loss of the chemical absorption system. Theoretically, the heat of reaction that needs to be supplied in order to reverse the absorption reaction is about $1.9 \mathrm{MJ} / \mathrm{kg} \mathrm{CO}$. But the actual amount of heat required is about 2-3 times higher. A wide range of numbers has been reported for the regeneration heat requirement of the MEA system. The majority of the sources reports a heat requirement of about $4 \mathrm{MJ} / \mathrm{kg} \mathrm{CO} \mathrm{CO}_{2}$ [26]. Singh et al. [27] modeled the MEA process for a 400 MWe coal fired power plant and found a specific thermal energy requirement equal to $3.8 \mathrm{MJ} / \mathrm{kg} \mathrm{CO}$, a value also used in this study. The heat is provided by low-pressure steam from the steam cycle of the combined cycle plant. The $\mathrm{CO}_{2}$ removal is limited both by low absorption and reaction rates and by the equilibrium conditions, so that a maximum removal rate of about $95 \%$ can be achieved.

In the simulation using IPSEpro the MEA scrubbing is considered by a model based on the energy and mass balance. The MEA unit works at a pressure of 20 bar, allowing a much smaller unit size compared to atmospheric conditions and improving the $\mathrm{CO}_{2}$ capture capability [28]. The syngas coming from the syngas cooler enters the capture unit with a temperature of $40^{\circ} \mathrm{C}$. Due to the exothermic absorber reaction the purified syngas leaves the unit at an elevated temperature of $65^{\circ} \mathrm{C} .95 \%$ of the $\mathrm{CO}_{2}$ is captured and leaves the stripper after passing a condenser at a temperature of $60^{\circ} \mathrm{C}$. Steam of 1.45 bar extracted in front of the low pressure turbine is fed to the capture unit to provide the regeneration heat. The steam is condensed in the reboiler and returned to the steam cycle, where it is mixed to the main flow after the condensate pump. The total amount of heat released in the reboiler is $323 \mathrm{MJ} / \mathrm{s}$ in order to capture $85 \mathrm{~kg} / \mathrm{s} \mathrm{CO}_{2}$. The purified syngas still contains small fractions of $\mathrm{CO}$ and $\mathrm{CO}_{2}$ which enter the combustion chamber of the gas turbine and are finally released to atmosphere so that only $90 \%$ of the carbon fed to the gasifier can be captured. The $\mathrm{CO}_{2}$ captured in the MEA unit is provided at a pressure of 20 bar, so that the energy consumption of further compression to 100 bar for transport and storage is relatively moderate $(85 \mathrm{~kJ} / \mathrm{kg} \mathrm{CO})$.

Power section: The syngas with a content of 91 vol.- $\%$ of hydrogen is heated up in a heat exchanger using hot syngas. In order to limit the NOx generation in the gas turbine combustion chamber nitrogen from the air separation unit is mixed to the syngas reducing the hydrogen content to 50 vol.-\% (see Table 1 ), a value generally guaranteed by gas turbine manufacturers [29]. The fuel gas with a LHV of $8.3 \mathrm{MJ} / \mathrm{kg}$ is fired in a combined cycle plant for power generation..

The hot exhaust gas leaves the combustor at a temperature of $1400^{\circ} \mathrm{C}$ and is fed to the turbine. Turbine cooling is considered by adding cold air from the compressor so that a mean turbine inlet temperature of $1300^{\circ} \mathrm{C}$ is achieved resulting in a cooling mass flow of $13.5 \%$ of turbine inlet mass flow. The combustion chamber pressure is set to 17.5 bar in order to achieve a turbine exit temperature of $610^{\circ} \mathrm{C}$ at an exit pressure of 1.04 bar. This inlet condition for the main heat recovery steam generator HRSG allows the operation of a dual-pressure reheat steam cycle. The corresponding steam pressure levels are 130 and 6 bar for high- and medium pressure turbine. The inlet pressure to the condensation turbine is 1.45 bar. The steam expands to a condensation pressure of 0.023 bar for a cooling water temperature of $10^{\circ} \mathrm{C}$ [22]. The steam cycle is closely connected with the gasification and the $\mathrm{CO}_{2}$ capture section by heat transfers as described above.

The stack temperature of the gas turbine exhaust gas is $92^{\circ} \mathrm{C}$. It has a very high steam content of 12.5 vol- $\%$ due to the hydrogen firing, so that $42.4 \mathrm{~kg} / \mathrm{s}$ makeup water has to be fed continuously to the cycle to close the mass balance.

\section{GRAZ CYCLE PLANT WITH COAL GASIFICATION}

Figure 4 shows the principle flow scheme of a Graz Cycle plant combined with a coal gasification unit. The detailed flow sheet used for the thermodynamic simulation is included in the appendix (Fig. 5) and gives mass flow, pressure, temperature and enthalpy of all streams. The Graz Cycle is an oxy-fuel cycle, where the syngas from the coal gasification is fired with pure oxygen. This allows the capture of all the carbon added to the gasifier, so that the energy-intensive shift reactors and MEA scrubber can be avoided. On the other hand, the amount of oxygen needed in the process nearly triples. Basically, the Graz Cycle consists of a high-temperature cycle (compressors $\mathrm{C} 1$ and $\mathrm{C} 2$, combustion chamber $\mathrm{CC}$, High-Temperature Turbine HTT, Heat Recovery Steam Generator HRSG and High Pressure Turbine HPT) and a low-temperature cycle (Low Pressure Steam Turbine LPST, condenser and compressors C3 and $\mathrm{C} 4)$.

Gasification section: Due to the higher net efficiency of this process, the thermal input to the gasifier is only $889 \mathrm{MJ} / \mathrm{s}$ $(30.29 \mathrm{~kg} / \mathrm{s}$ coal) to achieve a net electrical output of $400 \mathrm{MW}$. The auto-thermal reactor works at the same conditions of 25 


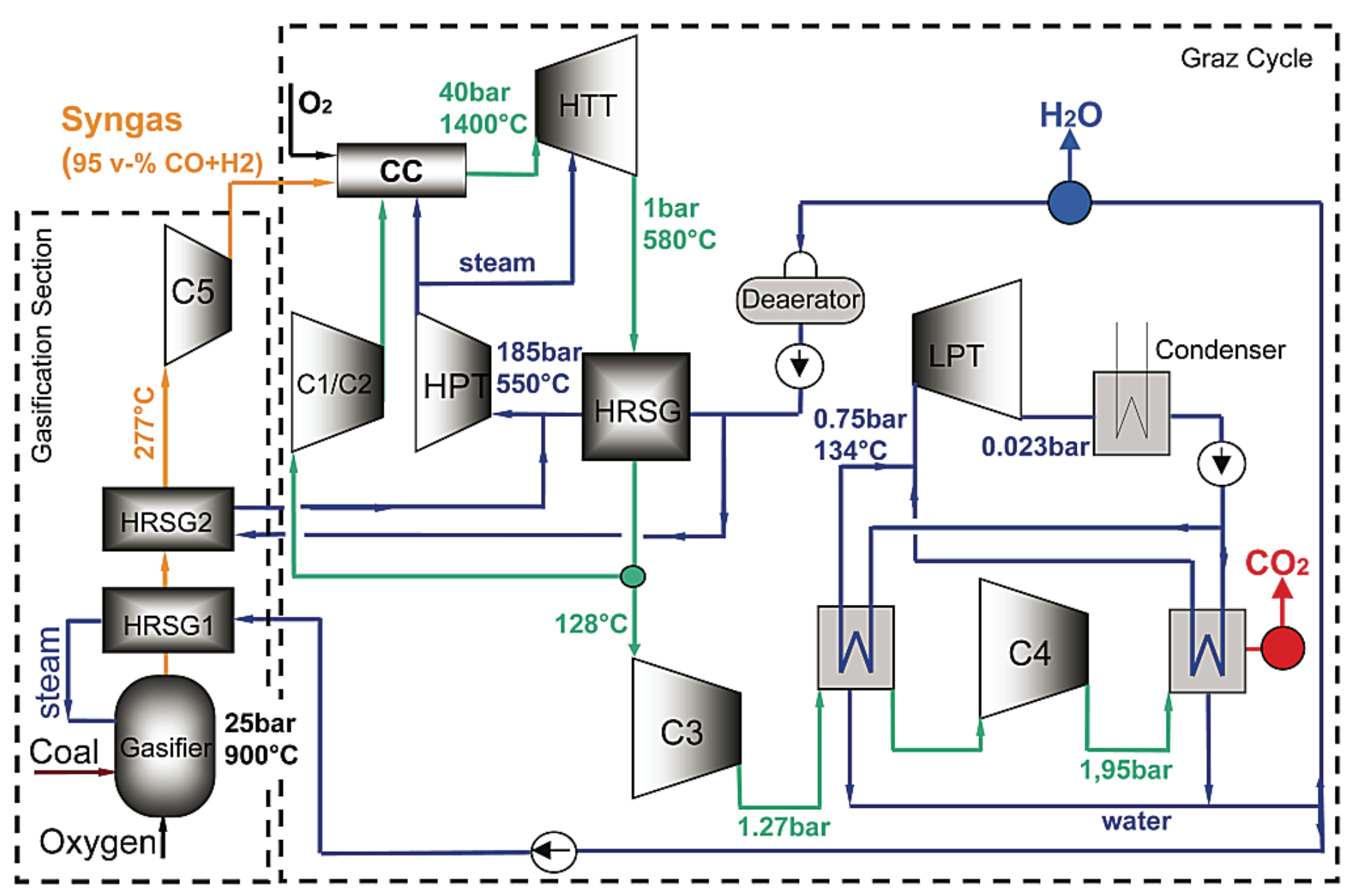

Fig. 4: Flow scheme of the Graz Cycle plant with coal gasification

bar and $900^{\circ} \mathrm{C}$. Again oxygen of $99 \%$ purity as well as steam has to be fed to the gasifier. The steam-to-coal ratio is set to 0.3 , which leads to a syngas of high heating value $(\mathrm{LHV}=14.2$ $\mathrm{MJ} / \mathrm{kg}$ ) with a content of the combustible gases $\mathrm{CO}$ and $\mathrm{H}_{2}$ of 95 vol-\% (see Table 2). The reaction temperature determines the necessary amount of oxygen of $20.5 \mathrm{~kg} / \mathrm{s}$, the stoichiometric ratio is 0.294 . The syngas is cooled in the succeeding HRSG1 to $685^{\circ} \mathrm{C}$, producing the steam for the gasifier. In order to further reduce the syngas temperature for gas cleaning and compression, it is cooled in the HRSG 2 to $277^{\circ} \mathrm{C}$ producing high-pressure steam for the Graz Cycle. A conversion of the $\mathrm{CO}$ to $\mathrm{CO}_{2}$ is not necessary, so that the water-shift reaction can be omitted. The syngas is then compressed to 41.7 and enters the combustion chamber of the Graz Cycle at a temperature of $393^{\circ} \mathrm{C}$.

Table 2: Syngas composition in vol-\% for Graz Cycle plant

\begin{tabular}{|c|c|c|c|c|c|}
\hline $\mathbf{C H}_{\mathbf{4}}$ & $\mathbf{H}_{\mathbf{2}}$ & $\mathbf{C O}$ & $\mathbf{C O}_{2}$ & $\mathbf{H}_{\mathbf{2}} \mathbf{O}$ & $\mathbf{N}_{\mathbf{2}}$ \\
\hline 0.1 & 39.2 & 56.0 & 2.1 & 1.8 & 0.8 \\
\hline
\end{tabular}

Graz Cycle power plant: In the Graz Cycle combustion chamber the syngas is burned with oxygen in an excess of $3 \%$ $(49.9 \mathrm{~kg} / \mathrm{s})$ provided additionally by the air separation unit and compressed to 41.7 bar. Steam drives the burner vortex core bringing together the reaction components. The high flame temperature is further reduced by the inflow of the working gas $\left(\mathrm{CO}_{2} / \mathrm{H}_{2} \mathrm{O}\right)$ around the burners and into the combustion chamber liner [12].

A mixture of about $64.0 \%$ steam, $35.2 \% \mathrm{CO}_{2}, 0.3 \% \mathrm{O}_{2}$ and $0.5 \% \mathrm{~N}_{2}$ (mass fractions) leaves the combustion chamber at a mean temperature of $1400^{\circ} \mathrm{C}$, a value exceeded by $\mathrm{G}$ and $\mathrm{H}$ class turbines nowadays. The fluid is expanded to a pressure of 1.06 bar and $579^{\circ} \mathrm{C}$ in the HTT. The HTT consists of a freerunning compressor turbine and a power turbine running at $3000 \mathrm{rpm}$ [10]. Cooling is performed with steam (12.9\% of the turbine inlet mass flow) coming from the HPT at about $327^{\circ} \mathrm{C}$, increasing the steam content to $68.0 \%$ at the HTT exit. Four of the total 7 stages are cooled. The hot exhaust gas is cooled in the following HRSG to vaporize and superheat steam for the HPT; the pinch point of the HRSG is $5^{\circ} \mathrm{C}$ (an aggressive value but used for both cycles), the approach point at the superheater exit is $28^{\circ} \mathrm{C}$. After the HRSG $\left(\mathrm{t}=128^{\circ} \mathrm{C}\right)$ about $45 \%$ of the 
cycle mass flow is re-compressed using the main cycle compressors $\mathrm{C} 1$ and $\mathrm{C} 2$. This splitting ratio is determined by the need that all combustion generated $\mathrm{CO}_{2}$ has to be delivered to the condensation process. Between $\mathrm{C} 1$ and $\mathrm{C} 2$ an intercooler is arranged. The $\mathrm{C} 1$ exit conditions are 13.7 bar and $482^{\circ} \mathrm{C}$, so that steam from the HRSG is superheated to $385^{\circ} \mathrm{C}$. The intercooler are chosen so that the $\mathrm{C} 2$ exit temperature is limited to $580^{\circ} \mathrm{C}$ for material reasons. The compressed working fluid is then fed to the combustion chamber at a temperature of $580^{\circ} \mathrm{C}$. $\mathrm{C} 1$ and $\mathrm{C} 2$ are driven by the HTT compressor turbine.

The remaining mass flow which contains the combustion generated $\mathrm{CO}_{2}$ is fed to a condensation process in the 1 bar range. The heat content in the flow is still quite high so reevaporation and expansion in a bottoming cycle is mandatory. For proper re-evaporation two sections of working fluid condensations are provided, each following a compressor stage with reasonable increase of flow pressure resulting in a higher partial condensation pressure of the water content. The heat exchangers are well developed modern boiler elements providing steam just below atmosphere $(0.75$ bar $)$ for the condensing steam turbine LPST.

The two pressure levels of 1.27 bar and 1.95 bar allow the segregation of $80 \%$ of the contained steam. Further cooling of the working fluid, also for water preheating, reduces the water content of the $\mathrm{CO}_{2}$ stream which is supplied at 1.7 bar for further compression, below $1 \%$. More details of the condensation/evaporation process can be found in [10]. After segregation of the water stemming from the combustion process, the water flow is degassed in the deaerator with steam extracted after the HPT and fed to the HRSG for vaporization and superheating. The steam is then delivered to the HPT at 185 bar and $550^{\circ} \mathrm{C}$. After the expansion it is used to cool the burners and the HTT stages.

The two-step condensation/evaporation counteracts the effect of sinking $\mathrm{H}_{2} \mathrm{O}$ partial pressure due to condensed water extraction from working fluid and thus allows reasonable steam inlet conditions of 0.75 bar and $134^{\circ} \mathrm{C}$ at the LPST inlet. Expanding the steam to a condensation pressure of 0.023 bar for a cooling water temperature of $10^{\circ} \mathrm{C}$ [22] provides about 13 $\%$ of the total plant power output.

Since the Graz Cycle is a semi-closed cycle, the steam used in the coal gasification process remains within the cycle, so that no make-up water is required.

\section{POWER BALANCE}

In order to assess the thermodynamic layout of the two power plants with $\mathrm{CO}_{2}$ capture a power balance of the two cycles in comparison with an IGCC plant based on the same gasification technology, but without any $\mathrm{CO}_{2}$ removal strategy, is presented in Table 3. All plants are laid out for a net plant output of $400 \mathrm{MW}$ which allows a better comparison of the component sizes.

At first, the net efficiencies of both IGCC plants without and with $\mathrm{CO}_{2}$ capture are elevated figures compared to other publications, e.g. [16]. So the reference IGCC plant shows an
Table 3: Power Balance

\begin{tabular}{|l|c|c|c|}
\hline & $\begin{array}{c}\text { Ref. } \\
\text { IGCC } \\
\text { plant }\end{array}$ & $\begin{array}{c}\text { IGCC } \\
\text { plant } \\
\text { w. CO } \\
\text { cap }\end{array}$ & $\begin{array}{c}\text { Graz } \\
\text { Cycle } \\
\text { plant }\end{array}$ \\
\hline Gas turbine expander/ HTT [MW] & 556 & 643 & 669 \\
\hline HP steam turbine [MW] & 70 & 85 & 63 \\
\hline MP steam turbine [MW] & 33 & 43 & \\
\hline LP steam turbine [MW] & 60 & 13 & 68 \\
\hline Total turbine power [MW] & $\mathbf{7 1 9}$ & $\mathbf{7 8 4}$ & $\mathbf{8 0 0}$ \\
\hline GT compressor / C1+C2 [MW] & 262 & 262.5 & 208.4 \\
\hline & & & \\
\hline Nitrogen compressor [MW] & & 39 & \\
\hline Syngas compressor [MW] & & & 11.2 \\
\hline C3+C4 compressor [MW] & & & 25.3 \\
\hline & & & \\
\hline Total compression power [MW] & $\mathbf{2 6 4}$ & $\mathbf{3 0 4}$ & $\mathbf{2 5 2}$ \\
\hline Net shaft power [MW] & 455 & 478.0 & 548.2 \\
\hline Total heat input [MW] & 788 & 1033 & 889 \\
\hline Thermal cycle efficiency [\%] & $\mathbf{5 7 . 4 7}$ & $\mathbf{4 6 . 3 2}$ & $\mathbf{6 1 . 7 2}$ \\
\hline $\begin{array}{l}\text { Electrical power output [MW] } \\
\text { considering. mechanical, } \\
\text { electrical \& auxiliary loss }\end{array}$ & 420.7 & 438.0 & 509.6 \\
\hline Electrical cycle efficiency [\%] & $\mathbf{5 3 . 4 1}$ & $\mathbf{4 2 . 4 0}$ & $\mathbf{5 7 . 3 4}$ \\
\hline $\begin{array}{l}\text { Oxygen generation \& } \\
\text { compression [MW] }\end{array}$ & 20.7 & 30.8 & 84.5 \\
\hline $\begin{array}{l}\text { Efficiency considering oxygen } \\
\text { supply [\%] }\end{array}$ & $\mathbf{5 0 . 7 9}$ & $\mathbf{3 9 . 4 1}$ & $\mathbf{4 7 . 8 4}$ \\
\hline CO ${ }_{2}$ compression (100 bar) [MW] & - & 7.2 & 25.2 \\
\hline Net power output [MW] & $\mathbf{4 0 0 . 0}$ & $\mathbf{4 0 0 . 0}$ & $\mathbf{4 0 0 . 0}$ \\
\hline Net efficiency [\%] & $\mathbf{5 0 . 7 9}$ & $\mathbf{3 8 . 7 1}$ & $\mathbf{4 5 . 0 1}$ \\
\hline
\end{tabular}

efficiency of $50.79 \%$ consistently higher than the one of plants now in operation. This is obtained by a very efficient configuration and by not considering all losses, especially from the syngas cleaning. Nevertheless, all three plants are simulated based on the same assumptions so that the differences between the different technologies can be obtained.

For the same net plant power of $400 \mathrm{MW}$ the HTT turbine of the Graz Cycle is the largest turbomachinery with $669 \mathrm{MW}$, the reference plant needs only a gas turbine expander of 556 MW due to the much higher plant efficiency. The steam turbines are of similar size besides the LP turbine of the IGCC plant with $\mathrm{CO}_{2}$ capture because of the steam extraction for the MEA regeneration. Regarding the compression power, the SGraz Cycle has the lowest demand because about half of the working fluid is recompressed in liquid form.

Looking at the net shaft power the Graz Cycle plant provides the most power with $548.2 \mathrm{MW}, 20 \%$ more than the IGCC reference plant and $15 \%$ more than the IGCC plant with 
$\mathrm{CO}_{2}$ capture. This is caused by the higher total turbine output and the lower total compression effort of the Graz Cycle plant. If all mechanical, electrical and auxiliary losses $(3 \%$ of total heat input) are deducted, the net electrical power reduces to 509.6 MW for the Graz Cycle plant, to $438 \mathrm{MW}$ for the IGCC plant with CCS and to only $420.7 \mathrm{MW}$ for the reference plant. This remarkably higher electrical output of the Graz Cycle is necessary in order to compensate the much higher efforts for oxygen supply and $\mathrm{CO}_{2}$ compression.

But looking at the total heat input by coal, the Graz Cycle is in-between both IGCC plants, which finally results in the highest thermal and electrical efficiency. The electrical efficiency for the Graz Cycle is calculated to $57.34 \%$, which is $3.93 \%$-points higher than for the reference plant because of the better approximation of the Graz Cycle to the ideal Carnot process as described in previous publications, e.g. [9-12]. The efficiency of the IGCC plant with CCS of $42.40 \%$ is the lowest by far. This is mainly caused by the high energy consumption needed in the MEA unit for the $\mathrm{CO}_{2}$ capture. The steam extraction in front of the low pressure steam turbine reduces its power by $75 \mathrm{MW}$.

The effort for the oxygen generation and compression shows only $20.7 \mathrm{MW}$ for the gasifier of the reference plant, leading to a net cycle efficiency of $50.79 \%$, a relatively elevated value as discussed above. The effort for the IGCC plant with CCS is $50 \%$ higher, i.e. $30.8 \mathrm{MW}$, because of the lower cycle efficiency and the higher stoichiometric ratio in the gasifier caused by the higher steam demand for the water-shift reaction. In the Graz Cycle plant $20.5 \mathrm{~kg} / \mathrm{s}$ oxygen are fed to the gasifier, and additional $49.9 \mathrm{~kg} / \mathrm{s}$ of higher pressure have to be supplied to the combustion chamber which increases the effort for the oxygen supply to $84.5 \mathrm{MW}$, i.e. $16.6 \%$ of the electrical power output. Looking at the efficiencies considering oxygen supply gives $39.41 \%$ for the IGCC plant with CCS and $47.84 \%$ for the Graz Cycle plant, so that the difference has reduced from $15 \%$-points in the electrical efficiencies to 8.4 $\%$-points.

The effort of $\mathrm{CO}_{2}$ compression to 100 bar for liquefaction is again smaller for the IGCC plant, because $\mathrm{CO}_{2}$ leaves the MEA unit at a pressure of 20 bar in contrast to 1.7 bar for the Graz Cycle plant. So the net efficiencies considering all additional efforts for $\mathrm{CO}_{2}$ capture are $45.01 \%$ for the Graz Cycle plant and only $38.71 \%$ for the IGCC plant. This remarkably higher efficiency of the Graz Cycle plant can be achieved for a carbon capture rate of nearly $100 \%$ in contrast to $90 \%$ for the IGCC plant. Chiesa and Lozza [30. 31] as well as Lozza et al. [3] reported in their study on $\mathrm{CO}_{2}$ abatement in IGCC power plants similar efficiencies for an oxy-fuel cycle as well as for post-combustion capture with physical absorption. The reference plant emitting all $\mathrm{CO}_{2}$ to the atmosphere achieves a net efficiency of $50.79 \%$, which is by $3 \%$-points larger than reported in [3].

\section{ECONOMIC EVALUATION}

The thermodynamic evaluation shows that a Graz Cycle plant offers a much higher efficiency and $\mathrm{CO}_{2}$ capture rate than an IGCC plant with pre-combustion $\mathrm{CO}_{2}$ capture. But whereas IGCC plants have already been operating world-wide for many years and demonstration plants with $\mathrm{CO}_{2}$ capture are running, a Graz Cycle plant still needs further research and development work. The authors showed in their publications on the Graz Cycle the feasibility of all components [6-13] but the step towards a demonstration plant is still big. Gas turbine manufacturers have to be confident that a Graz Cycle plant is also an economically attractive solution which will be of interest for utilities before they start developing the new turbomachinery needed.

Therefore, an economic comparison of the two alternatives of a power plant with $\mathrm{CO}_{2}$ capture is presented. The main indicator characterizing the economical performance of a power plant for $\mathrm{CO}_{2}$ capture are the costs of electricity $(\mathrm{COE})$ and the mitigation costs. The latter represent the increased capital and operational costs incurred by new and additional equipment and lower cycle efficiencies in relation to the $\mathrm{CO}_{2}$ mass flow avoided. The $\mathrm{CO}_{2}$ captured has an economic value, if it can be used for enhanced oil recovery (EOR) or in the future $\mathrm{CO}_{2}$ emission trading scenario (13€/ton $\mathrm{CO}_{2}$ in February 2010). These prices are very difficult to predict in the long term, but they form the threshold for the economic operation of zero emission power plants.

In order to estimate the mitigation costs, an economic comparison with the reference IGCC plant is performed. It is very difficult to estimate the investment costs of a power plant, especially if new components have to be considered. Recently a detailed cost estimate for an IGCC plant with $\mathrm{CO}_{2}$ capture was performed by Rodewald [32] leading to specific investment costs of $2328 € / \mathrm{kW}_{\mathrm{el}}$. Considering the results of the IPCC study on CCS [33] the costs of an IGCC plant without CCS are about $30 \%$ less, which would lead to specific costs of $1629 € / \mathrm{kW}_{\mathrm{el}}$.

Based on these numbers and following additional assumptions the economic evaluation is performed: 1) the yearly operating hours is assumed at $7800 \mathrm{hrs} / \mathrm{yr}$; 2) the capital charge rate is $12 \% / y r$, which corresponds to an interest rate of 8 $\%$ over a depreciation period of 15 years; 3 ) coal fuel costs are $1.1 \notin / \mathrm{kWh}_{\mathrm{th}}$; 4) for operation and maintenance $10 \%$ of the yearly capital costs are assumed, 5) the costs of $\mathrm{CO}_{2}$ transport and storage are not considered because they depend largely on the site of a power plant.

Table 4 shows the result of the economic evaluation. The capital costs contribute mostly to the costs of electricity (COE), and they differ by $1.07 \varnothing / \mathrm{kWh}_{\mathrm{el}}$ between the reference plant and the $\mathrm{CO}_{2}$ capture plants. But also the $\mathrm{COE}$ due to the fuel consumption differ remarkably. Finally, the COE for the reference plant add to $4.92 \notin / \mathrm{kWh}_{\mathrm{el}}$ compared to $6.78 \notin / \mathrm{kWh}_{\mathrm{el}}$ for the IGCC plant with $\mathrm{CO}_{2}$ capture and $6.38 \propto / \mathrm{kWh}_{\mathrm{el}}$ for the Graz Cycle plant. 
Table 4: Economic comparison for a $400 \mathrm{MW}$ plant

\begin{tabular}{|c|c|c|c|}
\hline & $\begin{array}{l}\text { Ref. } \\
\text { IGCC } \\
\text { plant }\end{array}$ & $\begin{array}{c}\text { IGCC } \\
\text { plant w. } \\
\mathrm{CO}_{2} \text { cap }\end{array}$ & $\begin{array}{l}\text { Graz } \\
\text { Cycle } \\
\text { plant }\end{array}$ \\
\hline Plant capital costs $\left[€ / \mathrm{kW}_{\mathrm{el}}\right]$ & 1629 & 2328 & 2328 \\
\hline \multicolumn{4}{|l|}{ Addit. capital costs $\left[€ / \mathrm{kW}_{\mathrm{el}}\right]$} \\
\hline $\mathrm{CO}_{2}$ emitted $\left[\mathrm{kg} / \mathrm{kWh}_{\mathrm{el}}\right]$ & 0.649 & 0.085 & 0.0 \\
\hline Net plant efficiency [\%] & 50.79 & 38.71 & 45.01 \\
\hline COE f. plant amort. $\left[\phi / k W h_{e l}\right]$ & 2.51 & 3.58 & 3.58 \\
\hline COE due to fuel $\left[\phi / \mathrm{kWh}_{\mathrm{el}}\right]$ & 2.17 & 2.84 & 2.44 \\
\hline COE due to O\&M $\left[\phi / \mathrm{kWh}_{\mathrm{el}}\right]$ & 0.25 & 0.36 & 0.36 \\
\hline Total COE $\left[\phi / \mathrm{kWh}_{\mathrm{el}}\right]$ & 4.92 & 6.78 & 6.38 \\
\hline \multicolumn{4}{|l|}{ Comparison } \\
\hline Differential COE $\left[\phi / \mathrm{kWh}_{\mathrm{el}}\right]$ & & 1.86 & 1.46 \\
\hline Mitigation costs $\left[€ /\right.$ ton $\mathrm{CO}_{2}$ ] & & 33.0 & 22.5 \\
\hline
\end{tabular}

Thus, the efforts of $\mathrm{CO}_{2}$ capture increase the COE of the IGCC plant by $1.86 \varnothing / \mathrm{kWh}_{\mathrm{el}}$. On the other hand, $\mathrm{CO}_{2}$ capture with a Graz Cycle plant leads to increased COE by only 1.46 $\notin / \mathrm{kWh}_{\mathrm{el}}$. Considering the amount of $\mathrm{CO}_{2}$ which can be avoided, this results in mitigation costs of $33.0 €$ per ton of $\mathrm{CO}_{2}$ avoided for the IGCC plant. The mitigation costs for a Graz Cycle plant are remarkably lower by a third and are only $22.5 € /$ ton $\mathrm{CO}_{2}$ avoided.

\section{SUMMARY AND CONCLUSIONS}

In order to satisfy the world's thirst for energy, coal will play an important role in the future energy supply despite its detrimental effect on the world climate. Therefore 'clean coal' strategies have to be developed to protect world's climate.

In this work two coal fired power plants with carbon capture technologies are investigated. The first plant is an IGCC plant with pre-combustion separation of generated $\mathrm{CO}_{2}$ and firing of the hydrogen-rich syngas in a combined cycle plant. The second plant is the Graz Cycle, an oxy-fuel plant of highest efficiency, where the syngas of the gasifier can be fired without further costly and energy-consuming treatment.

The thermodynamic investigation shows high energy penalties for the $\mathrm{CO}_{2}$ scrubber of the IGCC plant and for the oxygen supply of the Graz Cycle plant. The higher efforts of the Graz Cycle plant for oxygen supply and $\mathrm{CO}_{2}$ compression also lead to a remarkably higher shaft power for the same net power output. The electrical efficiency of the Graz Cycle plant is far higher than of the IGCC plant with $\mathrm{CO}_{2}$ capture and even higher than of an IGCC plant without a capture strategy. Finally, the net efficiencies show an efficiency penalty of 5.8 $\%$-points for the Graz Cycle and of $12.1 \%$-points for the IGCC plant compared with a reference plant without $\mathrm{CO}_{2}$ capture.

In a comparative economical analysis the Graz Cycle power plant also shows its superiority compared with the 'conventional' $\mathrm{CO}_{2}$ capture technology of the IGCC plant. The resulting $\mathrm{CO}_{2}$ mitigation costs of $22.5 € /$ ton $\mathrm{CO}_{2}$ are lower by a third and make it economically interesting in a future $\mathrm{CO}_{2}$ trading scenario.

So the authors believe that their Graz Cycle is a very efficient and feasible solution for a future CCS scheme. And its possibility to use syngas from coal gasification makes it also attractive for an emission-free use of coal as a relatively cheap and long-term available fuel.

\section{REFERENCES}

[1] IEA, 2009, "World Energy Outlook 2009 Fact Sheet", www.worldenerergyoutlook.org

[2] Anheden, M., Jacoby, J., 2009, "ENCAP Experience from the 30 MWth Oxyfuel Pilot Plant", European Conference on CCS Research, Development and Demonstration, Oslo, Feb. 2009

[3] Lozza, G., Romano, M., Giuffrida, A., 2009, "Thermodynamic Performance of IGCC with OxyCombustion $\mathrm{CO}_{2}$ Capture", S4FE2009 - International Conference on Sustainable Fossil Fuels for Future Energy, Rome, Italy

[4] Jericha, H., Sanz, W., Woisetschläger, J, Fesharaki, M., 1995, " $\mathrm{CO}_{2}$ - Retention Capability of $\mathrm{CH}_{4} / \mathrm{O}_{2}$ - Fired Graz Cycle", CIMAC Conference Paper, Interlaken, Switzerland

[5] Jericha, H., Fesharaki, M., 1995, "The Graz Cycle $1500^{\circ} \mathrm{C}$ Max Temperature Potential $\mathrm{H}_{2}-\mathrm{O}_{2}$ Fired $\mathrm{CO}_{2}$ Capture with $\mathrm{CH}_{4}-\mathrm{O}_{2}$ Firing", ASME Paper 95-CTP-79, ASME Cogen-Turbo Power Conference, Vienna, Austria

[6] Jericha, H., Göttlich, E., 2002, "Conceptual Design for an Industrial Prototype Graz Cycle Power Plant", ASME Paper 2002-GT-30118, ASME Turbo Expo 2002, Amsterdam, The Netherlands

[7] Jericha, H., Göttlich, E., Sanz,W., Heitmeir, F., 2003, "Design Optimisation of the Graz Cycle Prototype Plant", ASME Paper 2003-GT-38120, ASME Turbo Expo 2003, Atlanta, USA, Journal of Engineering for Gas Turbines and Power, Vol. 126, Oct. 2004, pp. 733-740

[8] Heitmeir, F., Sanz,W., Göttlich, E., Jericha, H., 2003, "The Graz Cycle - A Zero Emission Power Plant of Highest Efficiency", XXXV Kraftwerkstechnisches Kolloquium, Dresden, Germany

[9] Sanz, W., Jericha, H., Moser, M., Heitmeir, F., 2004 , "Thermodynamic and Economic Investigation of an Improved Graz Cycle Power Plant for $\mathrm{CO}_{2}$ Capture", ASME Paper GT2004-53722, ASME Turbo Expo 2004, Vienna, Austria, Journal of Engineering for Gas Turbines and Power, Vol. 127, Oct. 2005, pp. 765-772

[10] Sanz, W., Jericha, H., Luckel, F., Heitmeir, F., 2005, "A Further Step towards a Graz Cycle Power Plant for $\mathrm{CO}_{2}$ Capture", ASME Paper GT2005-68456; ASME Turbo Expo 2005, Reno-Tahoe, USA

[11] Jericha, H., Sanz, W., Göttlich, E., 2006, "Design Concept for Large Output Graz Cycle Gas Turbines", ASME Paper GT2006-90032, ASME Turbo Expo 2006, 
Barcelona, Spain; Journal of Engineering for Gas Turbines and Power, Vol. 130, Jan. 2008

[12] Sanz, W., Jericha, H., Bauer, B., Göttlich, E., 2007, "Qualitative and Quantitative Comparison of Two Promising Oxy-Fuel Power Cycles for $\mathrm{CO}_{2}$ Capture", ASME Paper GT2007-27375, ASME Turbo Expo 2007, Montreal, Canada; Journal of Engineering for Gas Turbines and Power, Vol. 130, May 2008

[13] Jericha, H., Sanz, W., Göttlich, E., Neumayer, F., 2008, "Design Details of a 600 MW Graz Cycle Thermal Power Plant for $\mathrm{CO}_{2}$ Capture", ASME Paper GT2008-50515, ASME Turbo Expo 2008, Berlin, Germany

[14] Princton Energy Resources International, 2003, "Assesment of the Commercial Potential for Small Gasification Combined Cycle and Fuel Cell Systems. Phase II Final draft report", www.perihq.com/ documents/Gasification-PhaseII-final-report 4-10-03.PDF

[15] Perry, R.H., 1999, "Perry's Chemical Engineers Handbook", McGraw-Hill Company

[16] Davison, J., Bressan, L., Domenichini, R., 2004, " $\mathrm{CO}_{2}$ Capture in Coal-Based IGCC Power Plants", Proceedings of the 7th International Conf. on Greenhouse Gas Control Technologies (GHGT7), Vancouver

[17] Beysel, G., 2009, "ASU -Technology Improvements enabling enhanced and more efficient CCS", 9th European Gasification Conference, Düsseldorf, Germany

[18] Statoil ASA, 2005, private communication

[19] Fiaschi, D., Lombardi, L., 2002, "Integrated Gasifier Combined Cycle Plant with Integrated $\mathrm{CO}_{2}-\mathrm{H}_{2} \mathrm{~S}$ Removal: Performance Analysis, Life Cycle Assessment and Exergetic Life Cycle", Int.J. Applied Thermodynamics, Vol.5, (No.1), pp.13-24

[20] Shirai, H., Hara, S., Kouda, E., Watanabe, H., Inumaru, J., Abe, T., 2005, "Conceptual Study of Highly Efficient Coal Gasification Combined Cycle Power Generation System with $\mathrm{CO}_{2}$ - capture with Oxygen Blown Coal Gasifier", 33rd International Technical Conference on Coal Utilization \& Fuel Systems, Clearwater, FL, USA

[21] SimTech Simulation Technology, 2009, "IpsePro Overview", http://www.simtechnology.com/IPSEpro

[22] 1996, "Turbine Blading Materials Boost", International Power Generation Journal, July 1996, pp. 65-67

[23] Alie, C., Backham, L., Croiset, E., Douglas, P.L., 2005, "Simulation of $\mathrm{CO}_{2}$ capture using MEA scrubbing: a flowsheet decomposition method", Energy Conversion and Management 46, pp. 475-487

[24] Renzenbrink, W., Ewers, J., Keller, D., Wolf, K.J., Apel, W., 2008, "RWE's 450 MW IGCC/CCS Project Status and Outlook", Energy Procedia, www.elsevier.com

[25] Abu-Zahra, M.R.M., Schneiders, L.H.J., Niederer, J.P.M., Feron, P.H.M., Versteeg, G.F., 2007, "CO capture from power plants, Part I. A parametric study of the technical performance based on monoethanolamine", International Journal of Greenhouse Gas Control 1, pp. 37 $-46$

[26] Rao, A.B., Rubin, E.S., Berkenpas, M.B., 2004, "An Integrated Modeling Framework for Carbon Management Technologies", Final Report to Contract No.: DE-FC2600NT40935, U.S. Dept. of Energy

[27] Singh, D., Croiset, E., Douglas, P., Douglas, M., 2003, "Technoeconomic study of $\mathrm{CO}_{2}$ capture from an existing coal-fired power plant: MEA scrubbing vs. $\mathrm{O}_{2} / \mathrm{CO}_{2}$ recycle combustion", Energy Conversion and Management 44, pp. 3073-3091.

[28] Desideri, U., Paolucci, A., 1999, "Performance modelling of a carbon dioxide removal system for power plants", Energy Conversion and Management 40, 1999

[29] Raddings, T., Jones, R., Scholz, M., 2009, “Gas Turbine Flexibility for Low Carbon Fuels", IChemE Gasification 9, Dusseldorf, Germany

[30] Chiesa, P., Lozza, G., 1999, " $\mathrm{CO}_{2}$ Emission Abatement in IGCC Power Plants in Semi-Closed Cycles: Part A With Oxygen-Blown Combustion", Journal of Engineering for Gas Turbines and Power, Vol. 121, Oct. 1999, pp. 635-641

[31] Chiesa, P., Lozza, G., 1999, "CO2 Emission Abatement in IGCC Power Plants in Semi-Closed Cycles: Part B With Air-Blown Combustion and $\mathrm{CO} 2$ Physical Absorption", Journal of Engineering for Gas Turbines and Power, Vol. 121, Oct. 1999, pp. 642-648

[32] Rodewald, A., 2008, „Kohlendioxidemissionsszenarien unter Berücksichtigung zukünftiger Stromerzeugungstechnologien", $\mathrm{PhD}$ thesis, Technical University Hamburg-Harbach, VDI Report No. 578

[33] Rubin, E., Meyer, L., de Coninck, H., 2005, "Carbon Dioxide Capture and Storage - Technical Summary", IPCC Special Report, www.ipcc.ch/ipccreports 


\section{APPENDIX}

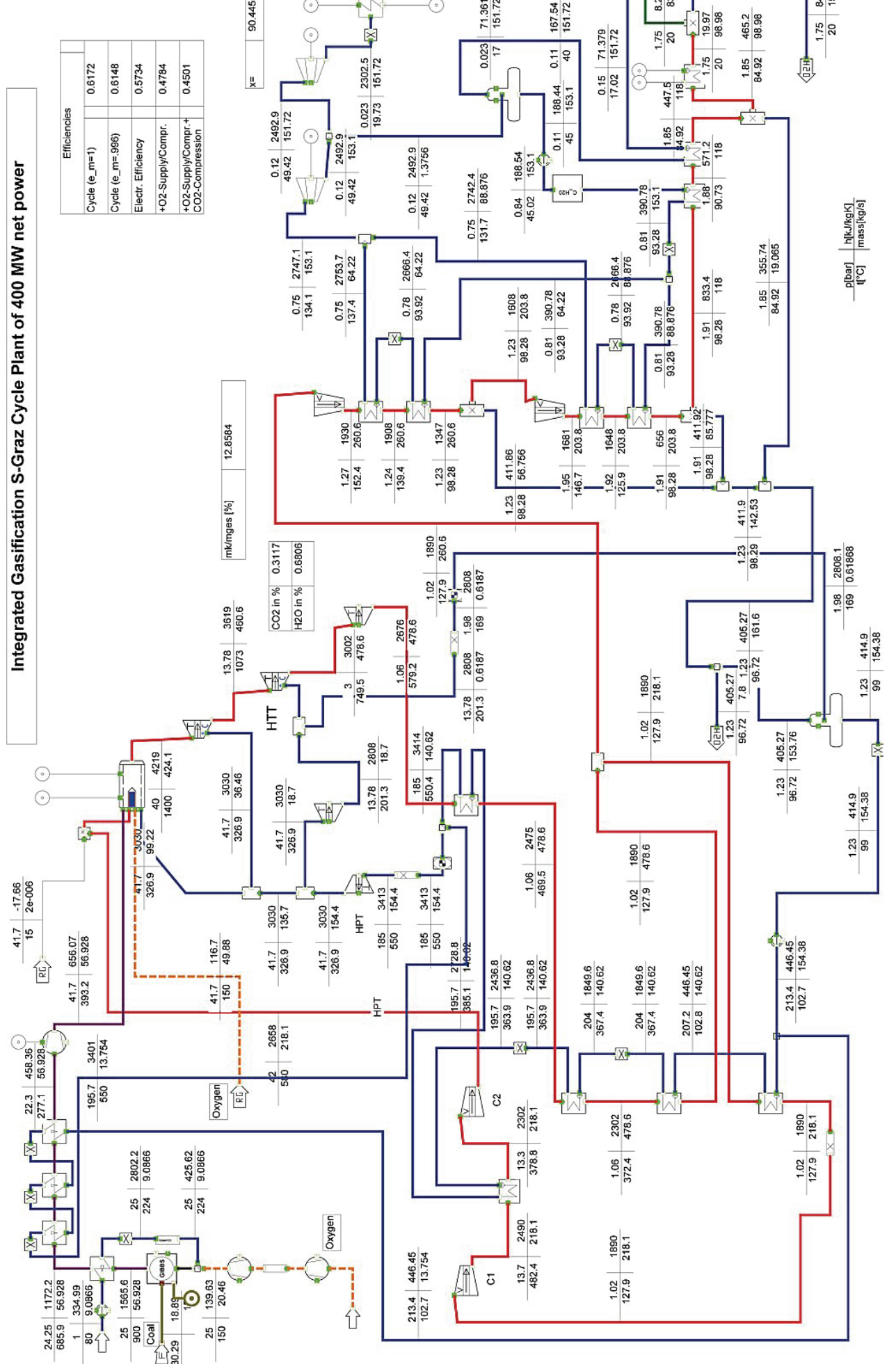

Fig. 5: Detailed thermodynamic cycle data of a 400 MW Graz Cycle power plant with integrated coal gasification 